\title{
Legal Considerations for Using Digital Twins in Additive Manufacture - A Review of the Literature
}

\author{
Jenny CLEMENTSON ${ }^{\mathrm{a}, 1}$, Dr Jason TENG ${ }^{\mathrm{b}}$, Dr Paul WOOD ${ }^{\mathrm{a}}$ and Dr Chris \\ WINDMILL $^{\mathrm{a}}$ \\ anstitute For Innovation In Sustainable Engineering, University of Derby, Quaker \\ Way, Derby DE1 3HD, UK \\ ${ }^{\mathrm{b}}$ Potter Clarkson LLP, The Belgrave Centre, Talbot Street, Nottingham NG1 5GG, UK
}

\begin{abstract}
Rapid technological change presents new opportunities and reveals new risks, challenging existing governance arrangements. The fusion of Industry 4.0 technologies combines with Additive Manufacturing (AM) to create new business solutions. Legal issues with AM are well documented, for example Daly[1] explores the interaction of 3D printing with the law, identifying Intellectual Property, Product Liability and Data Privacy as areas of importance. However, this technology fusion has also enabled improved real-time digital representation, monitoring, simulation and control of the physical delivered through applications of Digital Twin. Such Digital Twins are prevalent in manufacturing and in AM can potentially provide assurance that a printed item meets specified requirements. However, additional legal considerations are emerging. This paper illustrates these by examining the attributes of "Digital Twins in Additive Manufacture Use Cases" revealed through literature.
\end{abstract}

Keywords. Additive Manufacture, Industry 4.0, Legal Issues, Digital Twin

\section{Introduction}

Additive Manufacture (AM), building objects from digital models by depositing material layer by layer, provides opportunities for innovations compared to traditional subtractive manufacturing. Although there are claims that AM is still in its "formative phase"[2], the potential to harness benefits such as reducing waste and harm to the environment [2], to "significantly change certain production and distribution activities" [3], "decentralizing manufacturing" and "rationalising inventory and logistics" [4] is driving increasing interest. Since the technology was introduced there has been an increase in both economic and academic interest; for example, Ford[3] quotes an article from Wohlers in June 2013 which noted the number of articles published relating to AM rose from 1600 articles in 2011 to 16,000 in 2013. Osborn[5] comments that 3D printing was the "second fastest growing technology between 2013 and 2017 measured by published patent growth rate" and that revenues "enjoyed growth of $21 \%$ in 2017[5].

The World Economic Forum defines Industry 4.0 as the fusion of digital, physical and biological systems[6]. In addition to AM; this brings together other enabling

${ }^{1}$ Corresponding Author. j.clementson@derby.ac.uk 
technologies, particularly Artificial Intelligence, IoT and Big Data to enable Smart Manufacture and the increased use of so called "Digital Twins" which provide the opportunity to monitor, predict and control a system or manufacturing process by linking data between a physical system and a digital representation in real time.

This paper identifies AM Digital Twin attributes and then the legal considerations.

\section{Digital Twins in AM}

\subsection{Definition}

The Centre for Digital Built Britain's (cdbb) 'The Gemini Principles' defines a Digital Twin as a "realistic digital representation of something physical"[12]. It clarifies that a Digital Twin needs a data connection between the physical and digital model, such as data flows from sensors or current performance information. This is broadly similar to papers about manufacturing Digital Twins such as Kabaldin[14] and Hartmann[15]. The level of realism of the Digital Twin needs to be suited to its purpose and 'The Gemini Principles' identifies three essentials as the quality of the data on which the twin is based, the model (fidelity of algorithms, validity of assumptions and competence of code) and the quality of visualization of the output.

Within the manufacturing sector a report by Lanner's Chief Operating Officer, Andrew Aitken[13] identifies that Digital Twin means "different things to different people," and seeks to clarify different implementations and levels of deployment. It cites a presentation by Marc Thomas Schmidt, Chief Architect at GE Predix at Minds \& Machines 2017 who was quoted as defining Digital Twins as, "dynamic digital representations that enable companies to optimise the performance of their assets, processes and business"[13], clarifying the application to processes and business as well as assets. The paper defines three interconnected "levels" of Digital Twin as follows:

Table 1. Lanner Digital Twin Levels

\begin{tabular}{|c|c|c|}
\hline & Level & Guidance \\
\hline 1 & Asset Digital Twin & $\begin{array}{l}\text { Optimizing the design, manufacture and life-cycle of complex } \\
\text { assets, "usually at product or machine level."'[13] }\end{array}$ \\
\hline 2.1 & $\begin{array}{l}\text { Operational Process Digital Twin } \\
\text { - Supervisory Capability }\end{array}$ & $\begin{array}{l}\text { Mimicking "the running of real-life processes, either at the } \\
\text { operational or business level."[13] }\end{array}$ \\
\hline 2.2 & $\begin{array}{l}\text { Operational Process Digital Twin } \\
\text { - } \quad \text { Diagnostic and Control } \\
\text { Capability }\end{array}$ & $\begin{array}{l}\text { Linking "sensor data from the physical world to analytical and } \\
\text { data-mining algorithms to better understand and manage } \\
\text { process performance." [13] }\end{array}$ \\
\hline 2.3 & $\begin{array}{l}\text { Operational Process Digital Twin } \\
\text { - Predictive Capability }\end{array}$ & $\begin{array}{l}\text { "Using specially designed predictive simulation software to } \\
\text { evaluate planned or potential future scenarios." [13] }\end{array}$ \\
\hline 3 & Level 3 - Enterprise Digital Twin & $\begin{array}{l}\text { Capturing "the holistic business operating model for control } \\
\text { and management purposes." [13]. }\end{array}$ \\
\hline
\end{tabular}

While there are other definitions such as Qi et al [16], the Lanner [13] definition will be used to identify types of AM Digital Twins in the literature. 


\subsection{Digital Twin Applications Revealed in the Literature}

A search of the EBSCO Information Services Library Plus database ${ }^{2}$, revealed just a few key use case examples which are identified in Table 2.

Table 2. Academic Journal Search for Digital Twin in Additive Manufacture Use Cases

\begin{tabular}{|c|c|c|}
\hline Digital Twin Use Case & $\begin{array}{c}\text { Digital Twin } \\
\text { Level }\end{array}$ & $\begin{array}{l}\text { Literature } \\
\text { Reference }\end{array}$ \\
\hline $\begin{array}{l}\text { Detecting and Controlling Process Faults - applied to the } \\
\text { manufacture of Aerospace components using Directed Energy } \\
\text { Deposition (DED) and Laser Powder Bed Fusion (LPBF) }\end{array}$ & Level 2 & [7] \\
\hline $\begin{array}{l}\text { Traceability and transparency of every operation carried out in the } \\
\text { Aerospace supply chain relating to Additive Manufactured } \\
\text { products. (Scan \& Design, Build \& Monitor, Test \& Validate and } \\
\text { Deliver \& Manage) }\end{array}$ & Level 3 & [8] \\
\hline $\begin{array}{l}\text { Visualising and controlling the behaviour of a specific 3D printing } \\
\text { machine with the aim of reducing the amount of trial and error } \\
\text { testing, number of defects and shortening the time between design } \\
\text { and production. }\end{array}$ & Level $1 / 2$ & [9], [10], [11] \\
\hline Controlling the Robotic cleaning of 3D Prints & Level 2 & [14] \\
\hline
\end{tabular}

Further Use Case examples exist such as the DRAMA project[25] which developed a factory level Digital Twin controlling and optimize AM powder changes. Unsurprisingly Table 2 reveals a common driver for Digital Twins in AM in supporting product assurance and certification by better understanding and controlling processes to ensure the necessary product performance and physical properties are repeatedly delivered. This then drives product applications and the need for end to end traceability and data assurance for critical industrial applications.

\subsection{Generic AM Digital Twin}

Table 3 illustrates some general features of AM Digital Twins, relevant to the discussion of legal issues in section 3, which are revealed at each stage of the AM process.

Table 3. AM Digital Twin Features Relevant to Legal Considerations

\begin{tabular}{cl}
\hline $\begin{array}{c}\text { Process } \\
\text { Stages }\end{array}$ & \multicolumn{1}{c}{ Description and Example Features } \\
\hline $\begin{array}{c}\text { Scan \& } \\
\text { Design }\end{array}$ & $\begin{array}{l}\text { The design is encapsulated in a digital specification defined by the performance, function, fit } \\
\text { and form, which drives part geometry, manufacturing tolerances and material embodied in a } \\
\text { digital CAD file. The part CAD file is translated into a Surface Mesh File and then to a } \\
\text { Machine Instruction File using proprietary software at each step. Files can be edited/modified } \\
\text { at each stage. The Surface Mesh File may also be generated by 3D Scanning a physical object. }\end{array}$ \\
Build \& & $\begin{array}{l}\text { The Operator may manually set-up the AM control based on rules or experience or } \\
\text { recommendations from the Digital Twin or there may be some degree of automated control, } \\
\text { with Artificial Intelligence supporting control decisions. The material used is based on the }\end{array}$ \\
& $\begin{array}{l}\text { Designer's specifications in a form compatible with the chosen AM process. The Digital Twin } \\
\text { requires information/data about the specific design and operation of the AM system as well as } \\
\text { information from sensors. For a diagnostic, control or predictive, Level 2 Digital Twin, a } \\
\text { combination of bespoke and proprietary software and algorithms will be used to interpret real- }\end{array}$
\end{tabular}

${ }^{2}$ Searched on $14^{\text {th }}$ February 2020 using criteria "Additive Manufacturing" AND "Digital Twin" 
time information. Data is stored within the Digital Twin system to allow trend analysis and may link to other data sets and Digital Twins to support decision making.

Post- There can be further interfacing Digital Twins within the supply chain such as within the Process, processes of the Post-Processing and Testing/Certification sub-systems which will require data Test \& from the Scan \& Design process.

Validate

Deliver A Digital Twin of the product may be maintained during its operational life-time providing

\& further information on usage and performance which can be related back to manufacturing. Manage

A communications infrastructure communicates data between the AM System and Digital Twin in real-time. Data needs to be passed between various actors, such as the Designer, Operator, Post-Processor, Tester and Client. Technical Protection Measures (TPM) may be part of the Digital Twin architecture protecting data transactions.

\section{Legal Considerations}

Table 4 summarises the legal considerations from a sample of the literature. Some of the issues are then discussed in more detail together with approaches to risk mitigation.

Table 4. Summary of Legal Themes Mapped to Generic Digital Twin Features

\begin{tabular}{lr}
\hline \multicolumn{1}{c}{ Legal Considerations } & Sample Literature Reference \\
\hline Product Liability and Safety & {$[1],[5]$} \\
Intellectual Property & {$[1],[5],[17],[18],[19],[20]$} \\
Data Privacy, Data Sharing and Contracts & {$[5],[23],[24]$} \\
Theft/Malicious Data Interference and Cyber-Security breach & {$[21],[22],[24]$} \\
\hline
\end{tabular}

\subsection{Product Liability and Safety}

High value industrial items in critical applications, such as aerospace, for which there is significant investment in product and process design, require protection from unauthorized, uncontrolled printing, that digital files are not intentionally or accidently modified and there is full traceability through the manufacture and testing process. This ensures the integrity of the product. The introduction of decisions based on Artificial Intelligence also present issues for accountability in the case of an incident causing harm.

\subsection{Intellectual Property}

Various text books such as Daly[1] and Osborn[5] suggest that AM is disrupting IP laws and underlying policies. Daly[1] identifies the key points for AM Intellectual Property creation and infringement as the AM design embodied in the CAD file as code together with the software with which it interacts, elements of the design file that embody 'artistic' creation as well as the final, physical printed object, and online repositories for file upload and sharing. Osborn[5] notes, many objects are "utilitarian" and may not be easily protected in digital form. This is especially the case with the Surface Mesh File, which is "economically significant" [5] leading to a potential high risk of unauthorized manufacture from a misappropriated file or by digital scanning and reverse engineering, but Osborn[5] anticipates that for industrial applications contract law will be an 
important mechanism for managing risk. Even with contracts there are still risks where Digital Files and design and manufacture information is handled by third parties not subject to the original contract and the damages may be lower than for IP infringement. Widmer and Rajan[18] suggest a risk based approach to managing IP protection in AM which considers operational risk and legal uncertainties. Given early adopters of industrial AM Digital Twins are generally exposed to high operational risk and high legal uncertainty as well as more investment in product development, this suggests that AM Digital Twins will need to consider a range of legal and non-legal mitigations to include Intellectual Property protections and supply chain traceability for critical products.

\subsection{Data Privacy, Data Sharing and Contracts}

The effectiveness and potential scope of AM Digital Twins is dependent on access to reliable data. This includes data from the AM community, relating to how their printing machines, which are subject to Intellectual Property protections, perform. They in turn will be interested in improving their printing processes with access to the sensor data and testing and verification data within the Digital Twins. The Designer will also look for data to improve their design. At industry sector level, there is a need to define and implement data sharing agreements, looking for technical and contractual solutions which manage appropriate data[24] access for the benefit of the supply chain.

\subsection{Mitigation}

The available legal protections, throughout the supply chain, are inter-related. Any legal protections, including Intellectual Property (IP) protection of files, databases etc and contract arrangements for data sharing and management will work together with nonlegal protections such as TPM; encryption, tracking and digital water-marking, cybersecurity technologies, such as blockchain, and effective system design to mitigate risk.

\section{Conclusion}

This paper has given a high level illustration of the legal issues associated with AM Digital Twin. In industrial contexts, where designs and manufacturing processes have taken time and effort to create, there will be interest in driving legal and non-legal protection measures. Where there is potential benefit in sharing data in the development of processes, sharing agreements will emerge as well as shared technical approaches to deter malicious activity. Industrial sectors will drive both these legal and non-legal measures to achieve product assurance and economic benefits of AM. However, a legal framework or methodology for managing these risks through the sector supply chain, could assist industrial sectors drive forward AM Digital Twins to achieve these benefits.

\section{Acknowledgements}

The corresponding author acknowledges the support of the University of Derby for funding $\mathrm{PhD}$ research relating to legal issues with Digital Twin and the supervisory team and authors who directly contributed to review of this paper. 


\section{References}

[1] A. Daly, Socio-Legal Aspects of the 3D Printing Revolution, Palgrave Macmillan, London, 2016.

[2] A. Ghobadian, I.Talavera, A.Bhattacharya, V.Kumar, J.A.Garza-Reyes, N.O'Regan, Examining Legitimisation of Additive Manufacturing in the interplay between innovation, lean manufacturing and sustainability, International Journal of Production Economics 219 (2020), 457-468.

[3] S.L.N.Ford, Additive Manufacturing Technology: Potential Implications for U.S. Manufacturing Competitiveness, Journal of International Commerce and Economics, (2014), 1-35

[4] S.Mohr, O.Khan, 3D Printing and Its Disruptive Impacts on Supply Chains of the Future, Technology Innovation Management Review, 5(11) (2015), 20-25

[5] L.S.Osborn, 3D Printing and Intellectual Property, Cambridge University Press, Cambridge UK, 2019

[6] World Economic Forum Centre for the Fourth Industrial Revolution, https://www.weforum.org/centre-forthe-fourth-industrial-revolution/about (Accessed 14th June 2019)

[7] A.Gaikwad, R.Yavari, M.Montazeri, K.Cole, L.Bian, P.Rao, Toward the digital twin of additive manufacturing: Integrating thermal simulations, sensing, and analytics to detect process faults, IISE Transactions, (2020) DOI:10.1080/24725854.2019.1701753

[8] C.Mandolla, A.M.Pretruzzelli, G.Percoco, A.Urbinati, Building a digital twin for additive manufacturing through the exploitation of blockchain: A case analysis of the aircraft industry, Computers in Industry, 109 (2019), 134-152

[9] G.L.Knapp, T.Mukherjee, J.S.Zuback, H.L.Wei, T.A.Palmer, A.De, T.DebRoy, Building Blocks for a digital twin of additive manufacturing, Acta Materialia, 135 (2017), 390-399

[10] T.Mukherjee, T.DebRoy, A digital twin for rapid qualification of 3D printed metallic components, Applied Materials Today, 14 (2019) 59-65

[11] T.DebRoy, W.Zhang, J.Turner, S.S.Babu, Building digital twins of 3D printing machines, Scripta Materialia, 135 (2017), 119-124

[12] The Gemini Principles, cdbb, https://www.cdbb.cam.ac.uk/Resources/ResoucePublications/ TheGeminiPrinciples.pdf (accessed 18/06/2019)

[13] A. Aitken, Industry 4.0: Demystifying Digital Twins, Lanner, https://www.lanner.com/assets/User/2511Industry4.0 Demystifying the Digital Twin.pdf (accessed 21/02/2020)

[14] Y.G.Kabaldin, P.V.Kolchin, D.A.Shatagin, M.S.Anosov, A.A.Chusin, Digital Twin for 3D Printing CNC Machines, Russian Engineering Research 39 (2019), 848-851

[15] D.Hartmann, H.Van der Auweraer, Digital Twins, eprint arXiv:2001.09747 (2020),

[16] Q.Qi, F.Tao, Y,Zuo, D.Zhao, Digital Twin Service Towards Smart Manufacturing, Procedia CIRP 72 (2018), 237-242.

[17] S.Bechtold, Economic Research Working Paper No.28 3D Printing and the Intellectual Property System, WIPO Economic \& Statistics https://www.wipo.int/publications/en/details.jsp?id=3999\&plang=EN (accessed 2/5/19)

[18] M.Widmer, V.Rajan, 3D Opportunity for Intellectual Property Risk: Additive manufacturing stakes its claim, A Deloitte Series on Additive Manufacturing, Deloitte University Press www2.deloitte.com (accessed 2/5/19)

[19] Additive Manufacturing

UK, September

2016 https://www.ifm.eng.cam.ac.uk/uploads/Resources/Reports/AM_PUB_MTC_FINAL_FOR_PRINT_ne w-low_res.pdt (accessed 30/09/19)

[20] S.Bechtold, 3D Printing, Intellectual Property and Innovation Policy, International Review of Intellectual Property and Competition Law 47(5) IIC 517 (2016)

[21] A.Padmanabhan, J.Zhang, Cybersecurity Risks and Mitigations Strategies in Additive Manufacturing, Progress in Additive Manufacturing (2018) 3:87-93

[22] A.J.Hutchins, R.Bhinge, M.K.Micali, S.L.Robinson, J.W.Sutherland, D.Dornfield, Framework for Identifying Cybersecurity Risks in Manufacturing, Procedia Manufacturing, 1, (2015), 47-63

[23] W.Kerber, Governance of Data: Exclusive Property vs Access, IIC 47, (2016) 759-762 (Published online 27 October 2016, Max Planck Institute for Innovation and Competition, Munich 2016

[24] Y.Cui, S.Kara, K.C.Chan, Manufacturing Big Data Ecosystem: A Systematic Literature Review, Robotics and Computer Integrated Manufacturing 62 (2020), 101861

[25] Roberts, A, Loannou P, An Application for Predicting Environmental Conditions within an Additive Manufacturing Facility, COMSOL Technical Papers and Presentations, https://uk.comsol.com/paper/anapplication-for-predicting-environmental-conditions-within-an-additive-manufa-83141 (accessed $23 / 03 / 2020)$ 